\title{
The Specificity of Inflated Responsibility Beliefs to OCD: A Systematic Review and Meta-analysis of Published Cross-sectional Case-control Studies
}

\author{
Andrea Pozza ${ }^{1,2, *}$, Davide Dèttore ${ }^{2,3}$ \\ ${ }^{1}$ Department of Experimental and Clinical Medicine, University of Florence, Italy \\ ${ }^{2}$ Miller Institute for Behavioural and Cognitive Psychotherapy, Genoa, Italy \\ ${ }^{3}$ Department of Health Sciences, University of Florence, Italy \\ *Corresponding author: apsycho@hotmail.it
}

Received October 08, 2014; Revised November 25, 2014; Accepted December 04, 2014

\begin{abstract}
Leading cognitive theories posited that inflated responsibility beliefs play as a vulnerability and maintenance cognitive factor for obsessive compulsive disorder (OCD). A great body of research tested the specificity of responsibility to OCD, comparing on responsibility outcomes patients with OCD relative to normal controls or patients with anxiety disorders (AD). However, findings appeared inconclusive, and a systematic review summarizing evidence has not been conducted, yet. The current systematic review and meta-analysis provided a quantitative synthesis of findings from published cross-sectional case-control studies investigating whether inflated responsibility beliefs are specific to OCD. It was hypothesized that patients with primary OCD endorse stronger inflated responsibility beliefs compared to (1) healthy controls, and to (2) patients with any primary anxiety disorder. Electronic databases were searched. Cross-sectional case-control studies were included if they compared patients with primary OCD to healthy controls or patients with any primary anxiety disorder, and they used validated outcome self-report measures of responsibility. Studies conducted on primary hoarding were excluded. Studies on patients with comorbid conditions were not excluded. Twenty-two studies ( $n=8541$, 48 effect sizes overall) were included in random-effect meta-analyses. A large effect size favouring patients with OCD relative to controls was found $[d=1.13, \mathrm{SE}=0.09,99 \% \mathrm{CI}$ : 0.87-1.37, $p=0.0001]$. A medium effect size on responsibility favoring OCD over AD patients was found [d=0.66, $\mathrm{SE}=0.10,99 \% \mathrm{CI}: 0.39-0.92, p=0.0001]$, but the results appeared to be confounded by a publication bias effect. Current findings did not seem to confirm definitively the specificity of responsibility to OCD. Responsibility could be a transdiagnostic factor for psychopathology. Implications for caseformulation and treatment are discussed. Causal inferences on the role of responsibility in OCD development cannot be made due to the cross-sectional nature of studies. Further prospective studies are needed. Further research with experimental designs should address whether changes in responsibility beliefs mediate OCD symptom changes during cognitive behaviour therapy targeting the responsibility domain.
\end{abstract}

Keywords: obsessive compulsive disorder, inflated responsibility, beliefs, cognitive specificity, meta-analysis

Cite This Article: Andrea Pozza, and Davide Dèttore, "The Specificity of Inflated Responsibility Beliefs to OCD: A Systematic Review and Meta-analysis of Published Cross-sectional Case-control Studies." Research in Psychology and Behavioral Sciences, vol. 2, no. 4 (2014): 75-85. doi: 10.12691/rpbs-2-4-1.

\section{Introduction}

\subsection{The Specificity of Inflated Responsibility Beliefs to OCD}

Contemporary cognitive theories on the development and maintenance of Obsessive-Compulsive Disorder (OCD) are founded on Beck's cognitive specificity hypothesis [1], which proposes that particular types of psychopathology arise from particular types of dysfunctional beliefs. For example, depressive cognitive content was hypothesized to be focused on themes of negative self-evaluation, hopelessness, and generally pessimistic assessments of the world [2]. Consistently,
OCD might develop from dysfunctional beliefs concerning normally occurring intrusive thoughts, which may become distressing if they are interpreted in terms of personal responsibility [3].

Thus, inflated responsibility beliefs are hypothesized to play a role as a vulnerability and maintenance cognitive factor specific to OCD symptoms [4]. Salkovskis [3] suggested that inflated responsibility beliefs do persist due to a negative reinforcement process but also through the fact that they prevent the individual to verify that his/her beliefs are not realistic. Enduring inflated responsibility beliefs would be learned over long periods of time or as result of unusual or critical events [5]. Different pathways might lead to the development of maladaptive responsibility beliefs in persons predisposed to OCD, 
including the reinforcement of a generalized sense of responsibility for preventing threat, exposure to rigid and extreme codes of conducts and duty, or incidents involving action or inaction that significantly contributed to serious misfortune to self or others [4].

The specificity of inflated responsibility to OCD would be demonstrated if patients with OCD endorse responsibility beliefs more strongly than do patients with anxiety disorders or other forms of psychopathology [6]. If it were not the case, the model would not explain why individuals would have developed OCD symptoms rather than symptoms of anxiety disorders or other psychological conditions [6].

From the development of the cognitive models and the research work of the OCCWG, a large amount of studies has been conducted to date investigating whether inflated responsibility beliefs are specific to OCD [7]. In effect, some studies have suggested that patients with primary OCD endorse more strongly responsibility beliefs relative to healthy individuals or patients with other forms of psychopathology, including anxiety disorders or depression [6]. The relation of responsibility to OCD has been also supported by correlational research conducted on non-clinical samples of adults [8] and children or adolescents [9]. However, other studies produced conflicting findings, showing that responsibility was not a cognitive domain specific to OCD [10].

Cross-sectional investigations on the specificity of responsibility might have some implications for case formulation and treatment of OCD. In effect, this seems to have relevance since evidence on the relationship between inflated responsibility beliefs and outcome after cognitive behavioural therapy (CBT) appears still poor. For example, research to date suggested that the introduction of cognitive restructuring specifically targeting inflated responsibility did not seem to improve the efficacy of exposure with response prevention (ERP) alone, although cognitive techniques alone seem to be equally effective to ERP alone [11]. Consistently, inflated responsibility beliefs have been recently found to be a predictor of negative outcome after CBT for OCD [12]. Moreover, some studies have suggested a positive association between changes on the responsibility domain and treatment response after CBT [13]. However, such studies had some limitations including limited sample sizes. In addition, it should be considered that to date no process study based on repeated measurements investigated whether responsibility beliefs changes mediate symptom changes after CBT [14].

In conclusion, an approach concentrating on the specific beliefs that drive psychological factors involved in the maintenance of OCD, could also be central to advances made in the treatment of the disorder [15].

\subsection{Rationale and Hypotheses of the Current Study}

Evidence suggesting that OCD symptoms can occur without responsibility beliefs would be difficult to reconcile with the leading cognitive models of the disorder [16]. Despite the great deal of data from cross-sectional studies on the relations of inflated responsibility across OCD, anxiety disorders, and depression symptoms, evidence supporting the models appears still inconsistent [10], and a meta-analysis has not been conducted yet.

The current study used meta-analytic techniques to summarize findings from cross-sectional case-control studies to investigate whether inflated responsibility beliefs are specific to OCD. Specifically, the hypotheses of the studies were that:

1. patients with primary OCD endorse stronger inflated responsibility beliefs compared to healthy controls;

2. patients with primary OCD endorse stronger inflated responsibility beliefs compared to patients with any primary anxiety disorder.

\section{Method}

\subsection{Protocol of the Meta-analysis}

Objectives and methods of the current meta-analysis were specified in advance and reported in a protocol, which can be requested to the corresponding author (AP).

\subsection{Eligibility Criteria of the Studies}

The criteria considered for inclusion of the studies involved characteristics related to the Types of studies and designs, Types of participants, and Types of outcomes.

Types of studies and designs. Studies using crosssectional case-control designs were included. Studies were included if they had been reported in English, Italian, Spanish, French or German. Studies had to be published in peer-reviewed journals. No restriction on publication date was applied.

Types of participants. Studies were included if they involved clinical samples, and, specifically, patients who had a primary diagnosis of OCD or any primary anxiety disorder. The diagnoses had to have been made by a mental health professional through a structured or unstructured clinical interview according to a standardized classification system, such as the Structured Clinical Interview for the DSM-IV-TR Axis I Disorders. The patients had to present with a current diagnosis of OCD or anxiety disorders. Therefore, studies where the patients had a lifetime diagnosis were excluded. In addition, if the patients reported that he/she had a diagnosis in a period earlier than that in which the study had been carried out (e.g., the patients had reported a 12-month diagnosis of OCD), the study was excluded. If all the patients in the studies had a specific type of comorbidity (eg, all the sample patients had OCD and an additional diagnosis of Major Depressive Disorder), such studies were excluded. The rationale for this strategy was to improve the internal validity of the meta-analysis since studies on patients with OCD and a certain comorbidity might represent only a specific type of patients with OCD. However, if some of the patients in the study sample had comorbid disorders (eg, some patients in the study sample had comorbid mood disorders), such studies were not excluded. Indeed, as suggested by some authors [17], such an approach could improve external validity since patients with comorbid mood or anxiety disorders would be more representative of populations of referrals in primary and secondary care settings. For example, Major Depressive Disorder has been consistently found the most prevalent concurrent condition among patients with OCD [17], with 
a lifetime prevalence of approximately 50\% [18]. Studies were included if they had been conducted on outpatients or inpatients, and if they assessed patients with a diagnosis of mild to severe OCD. In addition, studies were included if they used patients on pharmacological treatments. The rationale for these three inclusion criteria was to increase external validity of the meta-analysis with the aim to represent patients with OCD across different settings and with different levels of OCD severity. Moreover, despite controlling for concurrent pharmacological treatments might improve the internal validity of the meta-analysis, it is likely to decrease its external validity as several patients with OCD are on medication at the time of seeking psychological help [19]. Studies conducted on compulsive hoarding were excluded since this condition is supposed to be a separate diagnosis in the DSM-5 [20]. Comorbid medical diseases were not excluded. No age restrictions were applied since the meta-analysis was conducted on children/adolescent and adult samples.

Types of outcomes. Studies were included if they used self-report measures to assess responsibility beliefs, validated and translated according to international standards [21]. Both measures of inflated responsibility developed by the OCCWG [22-23] and measures developed by other research groups, such the Responsibility Attitudes Scale [24], were included. Either studies using the Obsessive Beliefs Questionnaire-87 [OBQ-87; 22] and those using the Obsessive Beliefs Questionnaire-44 [OBQ-44; 23] were included.

\subsection{Information Sources and Search Procedure}

Studies were retrieved through online systematic literature searches, in which the key word "ObsessiveCompulsive Disorder” or key words indicative of anxiety disorders ("anxiety disorders", "generalized anxiety disorder", "social phobia”, "panic disorder") were combined with key words and text words indicative of "Responsibility" ("inflated responsibility”, "beliefs", “cognitions", "intrusions”, Obsessive Beliefs Questionnaire-87, Obsessive Beliefs Questionnaire-44, Interpretation of Intrusions Inventory, Responsibility Attitudes Scale, Responsibility Interpretation Questionnaire).

To select studies that could meet the selection criteria, the following databases were consulted: PsycINFO (January 1966-July 2014), PubMed (January 1966July2014), and Science Direct (January 1966-July 2014).

\subsection{Study Selection}

During the first two stages (rejection at title and at abstract), the titles and the abstracts of the papers identified through the systematic search, were read independently by the two reviewers (AP and DD). Where there was no agreement on inclusion at these two stages, the paper was retained. Subsequently, the full text of the papers passing this screen was read independently by the reviewers. Despite no formal assessment of agreement was performed, any between-assessors discrepancy on studies inclusion at this stage was resolved through discussion meetings.

\subsection{Meta-analysis}

\subsubsection{Summary Measures and Synthesis of Results}

Data were independently extracted by the two reviewers (AP and DD). Any disagreement was discussed through discussion meetings. To calculate the effect sizes, data were extracted from means, standard deviations and group sizes of the OCD groups or of the comparator groups. When this information was not available, conversion methods suggested by Ray and Shadish [25] were used. According to Hedges [26], Hedges' correction for small sample bias was applied to all effect sizes. Effect sizes of 0.80 or more were assumed to be large, 0.50 moderate, and 0.20 small [27]. As noticeable heterogeneity was expected across the included studies, effect sizes were computed using a random effects model. Random effect models assume that the included studies are drawn from populations of studies that systematically differ from each other. According to these models, effect sizes derived from included studies differ not only because of the random error within studies (as in the fixed effect model) but also because of true variation in effect sizes from one study to the other [28].

The $I^{2}$ statistic was computed in order to test for homogeneity of effect sizes. This statistic is an indicator of heterogeneity of effect sizes in percentages. A value of $25 \%$ or less indicates low heterogeneity, 50\% moderate, and over 75\% high [29]. Heterogeneity was also analyzed using the $Q$-statistic [30]. A significant $Q$ indicates that the variability across the effect sizes is greater than if it would have resulted from subject-level sampling error alone [30].

For all analyses, alpha was set to 0.01 .

\subsubsection{Publication Bias}

The likelihood of publication bias was analyzed using the fail-safe $N$ method [31]. This method consists of calculating the number $(N)$ of unpublished studies required to reduce the overall effect sizes to a nonsignificant level assuming that the effect sizes of such studies are equal to zero. As recommended by Rosenthal [31], this value was computed according to the following formula: $N=k(k Z-2.706) / 2.706$ where $k$ is the number of studies included in the meta-analysis and $Z$ is the mean derived form $k$ studies.

Subsequently, the Egger test [32] was applied to examine a publication bias effect. The Egger test is an unweighted regression based on the precision of each study as the independent variable ${ }^{1}$ and the Effect Size divided by its standard error as the dependent variable. A non-statistically result of the $t$-test for the null hypothesis of an intercept equal to zero, allows to discard publication bias [32].

The meta-analysis was conducted using the software Comprehensive Meta-Analysis version 2.0.

\section{Results}

\subsection{Study Selection}

The electronic search and the search through additional sources produced 198 records after duplicates removed.

\footnotetext{
${ }^{1}$ Precision was defined as the inverse of the standard error of each Effect Size.
} 
Of those studies, 71 and 94 were excluded at title or at abstract respectively, as they were on irrelevant constructs. Thus, 33 studies were screened at full-text for inclusion. Of those studies, 4 studies were excluded as they did not use validated measures of responsibility beliefs. Three studies were excluded as they were based on prospective designs. Four studies were excluded as they examined the relation of responsibility to OCD dimensions.

After this selection, twenty-two studies were included in the current meta-analysis by consensus of the two independent assessors ( $n=8541,48$ effect sizes overall). The Flow Chart of the selection process is provided in Figure 1.

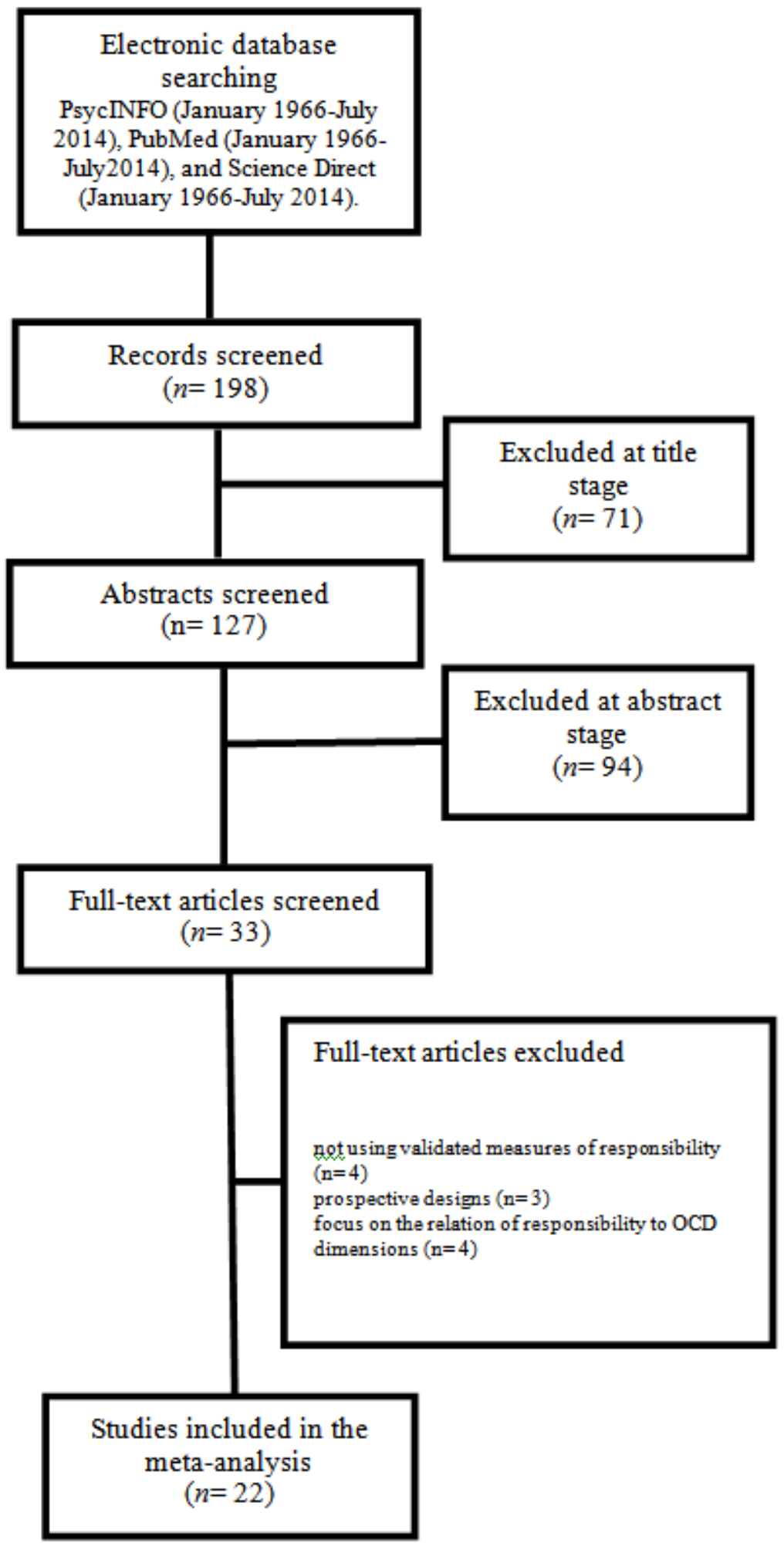

Figure 1. Flowchart of the study selection process

\subsection{Study Characteristics}

All the included studies had been published in peerreviewed journals. Twenty-one studies compared on responsibility beliefs outcomes patients with OCD and healthy participants as controls. Sixteen studies compared patients with OCD and patients with primary anxiety disorders. Ten studies were conducted on adult samples, 
two studies on adolescent or children samples. In fourteen studies diagnoses of OCD were made through the Structured Clinical Interview for the DSM-IV Axis I disorders (SCID-I), in eight studies through the Anxiety Disorders Interview Schedule for DSM-I (ADIS-IV), in three studies exclusively through a non-structured clinical interview based on the DSM-IV or DSM-IV-TR criteria.

Three studies were conducted in the Netherlands [33,34,35], two studies in Brazil [36,37], three studies in the USA $[38,39,40,41]$, four studies in the UK
$[24,42,43,44]$, two studies in Iran $[45,46]$, two studies in Canada $[47,48]$, two studies in Italy $[49,50]$, one study in Turkey [51], and two were multicentre studies [22,23]. Total sample sizes ranged from 1217 to 594 participants. Sixteen studies used measures of inflated responsibility beliefs developed by the OCCWG.

Publication date of the studies ranged from 1995 to 2013.

Descriptive characteristics for each of the included studies are reported in Appendix A.

\begin{tabular}{|c|c|}
\hline Study гете & Concaison \\
\hline Artolt 2004 & $0 \mathrm{CD}$ is tedthy outma $\mathrm{BO}-\mathrm{Br}$ \\
\hline Arhot 2006 & $0 \mathrm{CD}$ is tedtyoutrde $\mathrm{BO}-8 \mathrm{8}$ \\
\hline Bijier \& vide 208 & $0 \mathrm{CD}$ is tedty out de $\mathrm{B} 0-31$ \\
\hline Bijiei 200 & $0 \mathrm{CD}$ is hedtyoutma $\mathrm{BO}-31$ \\
\hline $\operatorname{ark} 2010$ & 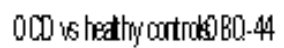 \\
\hline Couge 2007 OCDodeding & OCD is hedty ortmolses \\
\hline \multicolumn{2}{|c|}{ 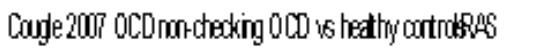 } \\
\hline Ghassertradeh 205 & $0 \mathrm{CD}$ is hedtry cortmbses \\
\hline Gondon 013 & OCD is hedthy outmoses \\
\hline Izadi & $0 \mathrm{CD}$ is tedthy ortmde $\mathrm{BO}-44$ \\
\hline Jien2000 & $0 \mathrm{CD}$ is hedty out dis $\mathrm{BO}-44$ \\
\hline Itby 204 & OCD is tedty ortrodses \\
\hline Nouga 200 & 000 is hed thy out rodentined \\
\hline ocanos 203 & 0,0 is tedty ortmolfontiod \\
\hline ocanin $2 \pi 3$ & 0,00 is tedthy cortmountined \\
\hline 0.000 2015 & 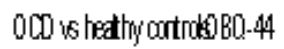 \\
\hline $0 \operatorname{con} 200$ & $0 \mathrm{CD}$ is tedthy outrde $\mathrm{BO}-44$ \\
\hline Padortsoy 201 & $0 \mathrm{CD}$ is tedtyoutmd $\mathrm{BO}-44$ \\
\hline Sacoudis 200 & 000 is tedtry outmonses \\
\hline $5 \mathrm{sic} 204$ & 000 is bedty ortedifuntined \\
\hline Tón 2016 & $0 \mathrm{CD}$ is hedtyoutma $\mathrm{BO}-44$ \\
\hline Via 2011 & $0 \mathrm{CD}$ is hedtyoutrde $\mathrm{BO}-44$ \\
\hline Winters 2011 & 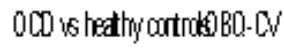 \\
\hline Yontra 208 & $0 \mathrm{CD}$ is hedthy ortmotes \\
\hline
\end{tabular}

$-4,00$

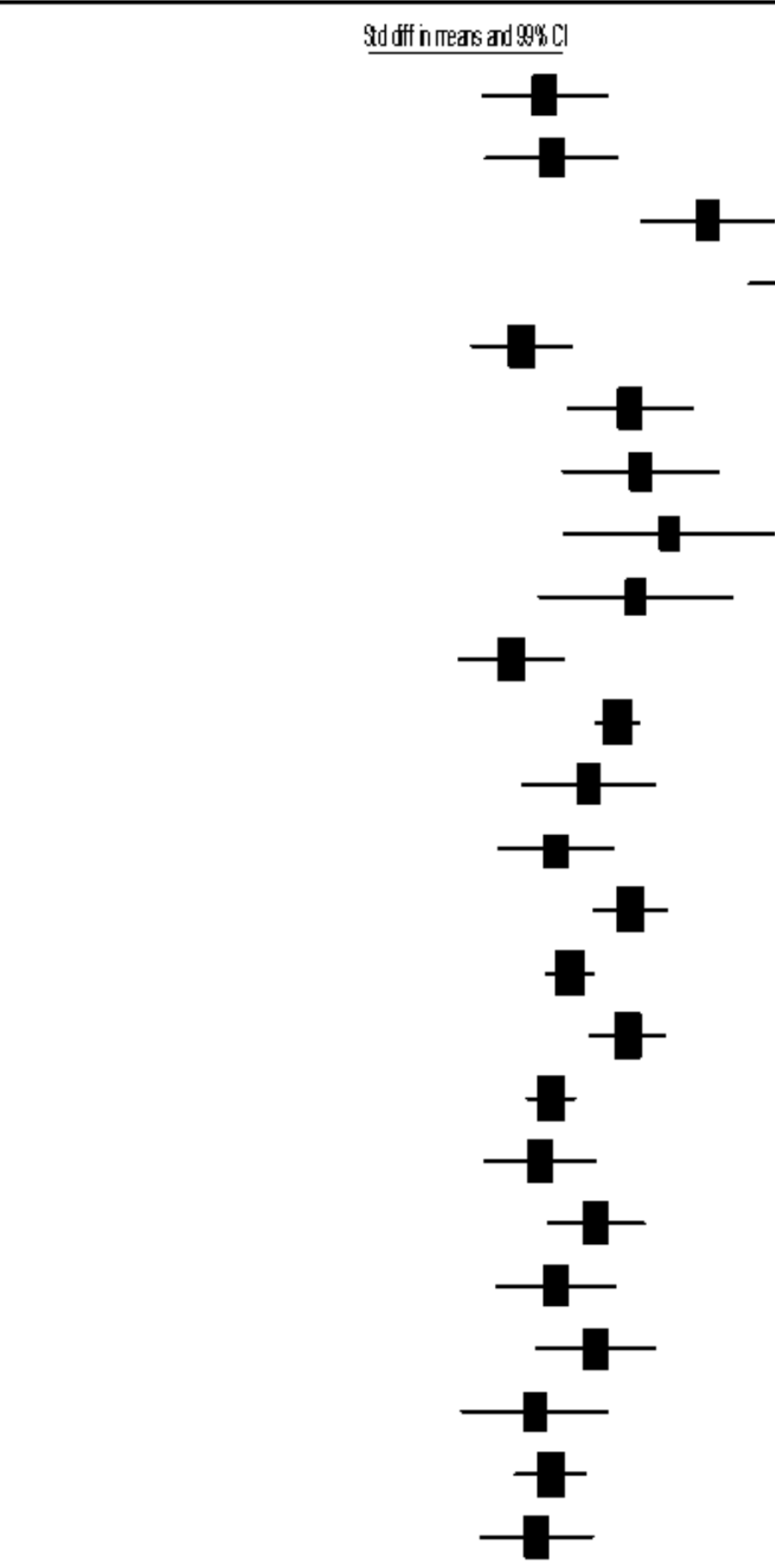




\subsection{Comparison on Inflated Responsibility Beliefs Outcomes between Patients with Primary OCD and Healthy Controls}

This analysis included 21 studies with 24 effect sizes $(n=4913)$. Results showed a large effect size $[\mathrm{d}=1.14$, $\mathrm{SE}=0.09$, 99\% CI: $0.90-1.39, p=0.0001]$, suggesting that patients with OCD had significantly higher scores on responsibility outcomes relative to healthy controls.A large heterogeneity was found $\left[I^{2}=85.87, Q=162.79 p=\right.$ 0.0001]. The forest plot with study and mean effect size comparing on responsibility outcomes patients with OCD and healthy controls is provided in Figure 2.

Overall, these results did not seem to be attributable to the effect of a publication bias, since the Classic Fail-Safe $\mathrm{N}$ index suggested that it would require 5707 unpublished studies to bring the effect size to a non-significant level, and the Egger test resulted non-significant [Intercept= 1.13, $t=0.86$, 2-tailed $\mathrm{p}=0.39]$.

Subsequently, in order to increase internal validity of the results, the analyses were restricted to studies using pure measures of responsibility beliefs, not covering also items on threat overestimation (i.e. studies using the OBQ-87, the Interpretations of Intrusions Inventory, and the Responsibility Attitudes Scale). Results with 11 studies (13 effect sizes, $n=1905$ ) indicated a large effect size, favouring patients with OCD relative to controls $[d=1.13, \mathrm{SE}=0.09,99 \% \mathrm{CI}: 0.87-1.37, p=0.0001]$.The funnel plot of effect sizes comparing on responsibility beliefs outcomes patients with OCD versus healthy controls is presented in Figure 3.

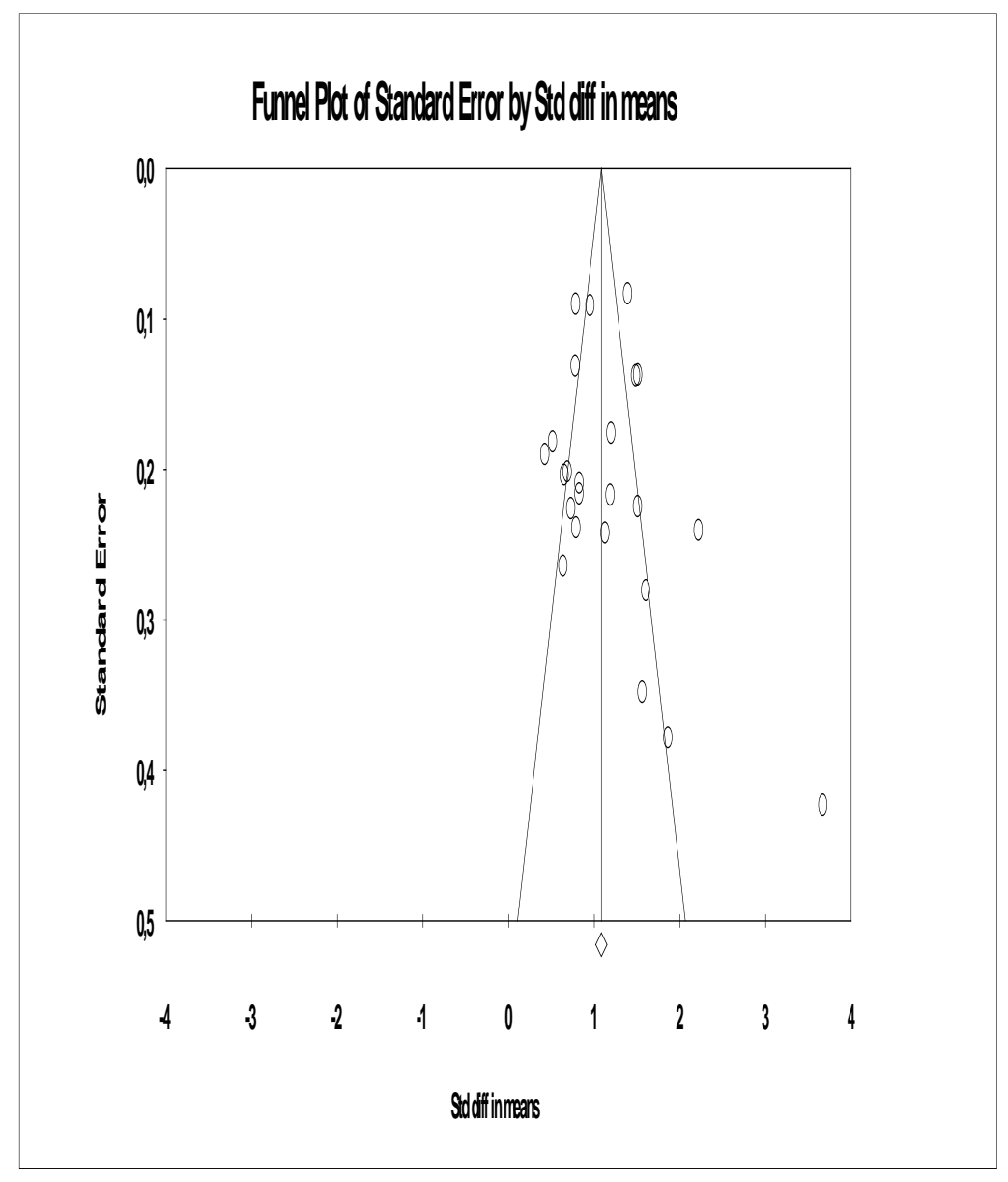

Figure 3. Funnel plot of effect sizes on the comparison between patients with OCD and healthy controls on responsibility beliefs outcomes

\subsection{Comparison on Inflated Responsibility Beliefs Outcomes between Patients with Primary OCD and Patients with Primary Anxiety Disorders}

This analysis included 16 studies with 20 effect sizes $(n=2079)$. Results showed a moderate effect size $[d=0.66$, $\mathrm{SE}=0.10,99 \% \mathrm{CI}: 0.39-0.92, p=0.0001]$, suggesting that patients with primary OCD had significantly higher scores on responsibility outcomes relative to patients with primary anxiety disorders. The forest plot with study and mean effect size comparing on responsibility outcomes patients with OCD and patients with primary anxiety disorders is provided in Figure 4.
Despite the Classic Fail-Safe N index suggested that it would require 567 unpublished studies to bring the effect size to a non-significant level, the Egger test resulted significant [Intercept $=3.98, t=4.10,2$-tailed $p=0.001$ ], suggesting that these results might be attributable to the effect of a publication bias. Subsequently, when the analyses were restricted to studies using pure measures of responsibility beliefs (eight studies, nine effect sizes, $n=$ 900), a moderate effect size was found favouring patients with OCD relative to patients with anxiety disorders [ $d=0.65 \mathrm{SE}=0.11,99 \% \mathrm{CI}: 0.42-0.88, p=0.0001]$.

The funnel plot of effect sizes comparing on responsibility beliefs patients with OCD versus patients with anxiety disorders is presented in Figure 5. 


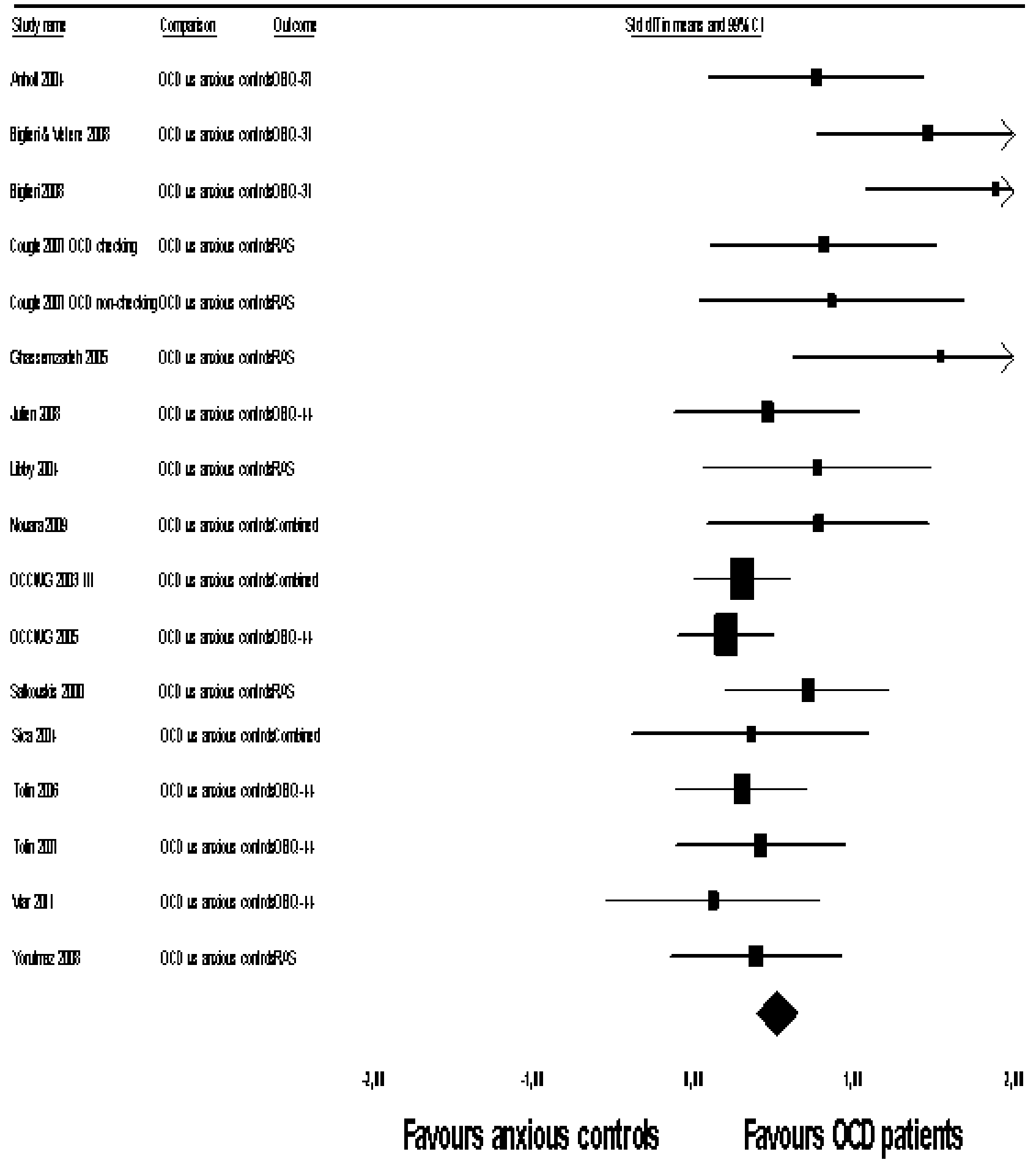

Figure 4. Forest plot with mean and study effect sizes on the comparison between patients with OCD and healthy controls on responsibility beliefs outcomes

\section{Discussion and Conclusions}

\subsection{Synthesis of Findings}

The leading cognitive models of OCD posited that inflated responsibility beliefs play as a vulnerability and maintenance cognitive factor for obsessional thinking [3,52]. Despite the increasing amount of research providing data to test for such models, a systematic review on this topic does not exist. Thus, the current study summarized available evidence from cross-sectional investigations examining the specificity of inflated responsibility beliefs to OCD relative to anxiety disorders. The specificity of responsibility to OCD was assessed locating and including cross-sectional case-control studies where patients with primary OCD were compared on responsibility outcomes to patients with primary anxiety disorders or healthy controls. Twenty-two published studies were included in the meta-analysis. In line with the models, comparisons between patients with OCD and healthy controls on responsibility outcomes indicated a large mean effect size favouring patients with OCD, showing that this group endorsed more severe responsibility beliefs relative to healthy controls. These findings did not appear to be attributable to a publication 
bias effect. In addition, such results were confirmed also when by sensitivity analyses the calculations of effect sizes were restricted to studies using pure measures of responsibility, such the OBQ-87.

In partial contrast with the cognitive models, the comparison between patients with OCD and patients with a primary anxiety disorder on responsibility outcomes yielded a moderate mean effect size favouring the clinical group. However, it should be noted that for this result a high likelihood for a publication bias was found, suggesting the need for further studies addressing this hypothesis. Thus, it could be hypothesized that inflated responsibility beliefs may be associated also with symptoms of different forms of psychopathology other than OCD, specifically anxiety disorders. A possible explanation could be that responsibility beliefs play as a transdiagnostic cognitive factor for both OCD and anxiety disorders. Alternatively, the relation of responsibility to both OCD and anxiety disorders could be explained by a higher-order factor, such as negative affect, a construct which has been shown to act as a common diathesis for emotional disorders [53]. Consistently, such common diathesis might explain the relatively high rates of comorbidity between OCD and anxiety disorders observed by previous research [18].

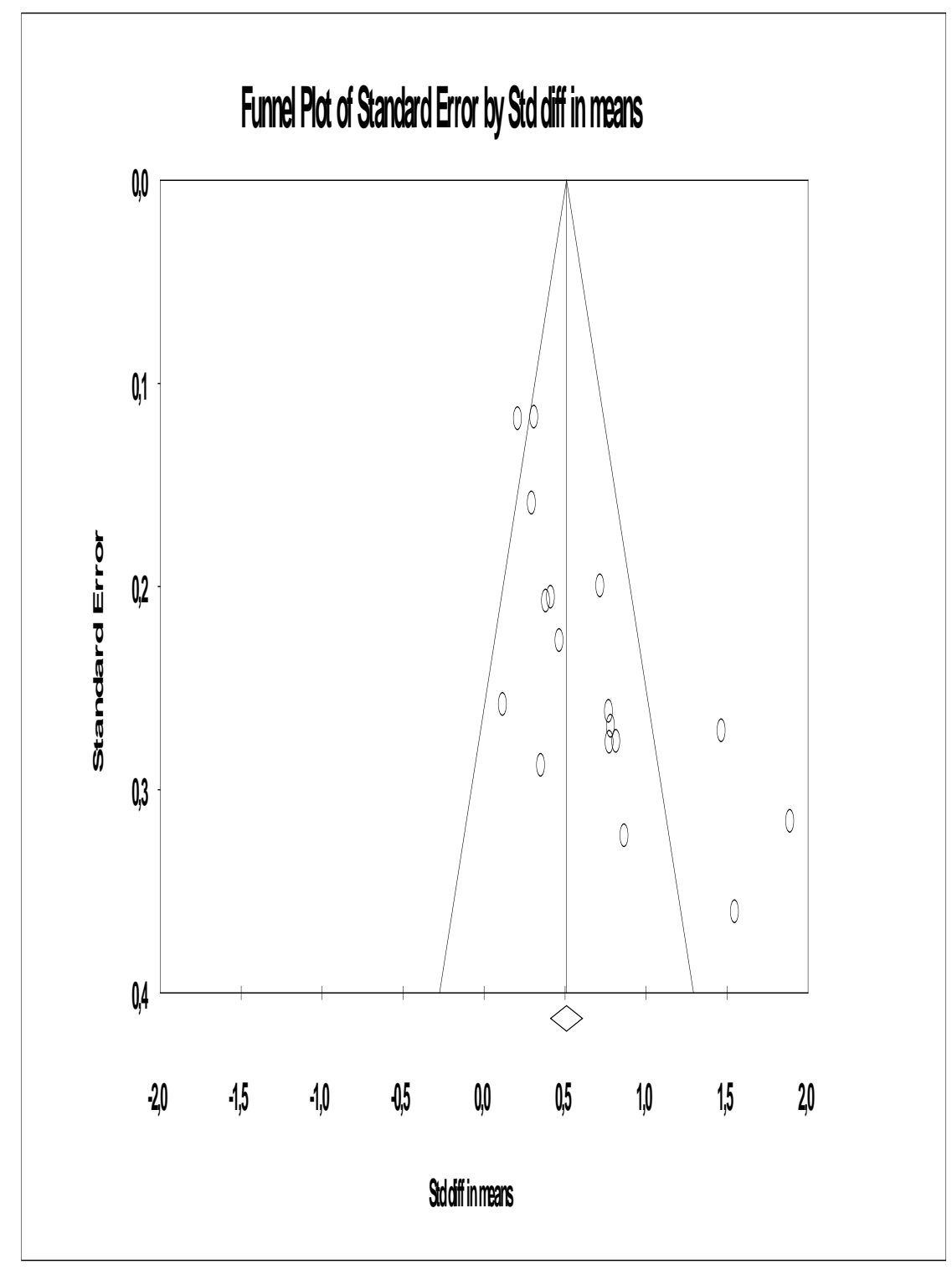

Figure 5. Funnel plot of effect sizes on the comparison between patients with OCD and patients with primary anxiety disorders on responsibility beliefs outcomes

In conclusion, findings only partially supported assumptions proposed by the models of OCD. Therefore, further studies are required to conclusively determine whether responsibility beliefs are associated to OCD or to psychopathology in general. Indeed, the current findings seemed to have clinical implications, since responsibility domain could be integrated in case formulation and used as a treatment target also for other forms of psychopathology, including anxiety disorders, such as in transdiagnostic unified procotols [54].

\subsection{Limitations and Implications for Future Research}

The current findings should be considered in the context of some limitations. First, only studies with crosssectional designs were included, due to the limited number of studies conducted according to prospective designs. This limitation did not allow to draw conclusions on the causal relationship between inflated responsibility and 
development of OCD. It could be hypothesized that inflated responsibility beliefs are a secondary effect of functional impairment and simptom severity in individuals suffering from a mental disorder, instead of believing that such cognitions play as a vulnerability and maintenance factor. Thus, further research based on prospective designs with long-term time-points of assessments is required to investigate whether stronger responsibility beliefs play as a predictor of OCD symptom onset. Similarly, to test for the specificity of responsibility would require that changes in responsibility beliefs mediate changes in OCD symptoms. However, to our knowledge a very small amount of studies tested for this hypothesis [eg, 55], thus preventing to conduct a meta-analysis. Therefore, future process studies examining outcome mediators are needed.

In addition, the small number of available studies also precluded to investigate whether the specificity of responsibility would vary as a function of OCD symptom dimensions. Accordingly, inconsistent findings have been provided on the relation of inflated responsibility to OCD dimensions, with some studies suggesting that responsibility beliefs might be specific to checking and doubting rather than cleaning compulsions [eg, 56], and other studies showing that they might be related to all the OCD dimensions [eg, 7]. In addition, it should be noted that inflated responsibility might not be a stable personality trait, but instead may be more idiosyncratic and situationally determined than originally formulated [57].

\section{References}

[1] Beck AT. (1976). Cognitive therapy and the emotional disorders. International Universities Press, New York.

[2] Clark, D.A., Beck, A.T. and Brown, G., "Cognitive mediation in general psychiatric outpatients: A test of the content-specificity hypothesis”, Journal of Personality and Social Psychology, 56. 958. 1989.

[3] Salkovskis, P.M., "Obsessional-compulsive Problems: A cognitive-behavioural analysis”, Behaviour Research and Therapy, 23. 571-583. 1985

[4] Salkovskis, P.M., Shafran, R., Rachman, S. and Freeston, M.H., "Multiple pathways to inflated responsibility beliefs in obsessional problems: possible origins and implications for therapy and research”, Behaviour Research and Therapy, 37. 1055-1072. 1999.

[5] Salkovskis, P.M. and Freeston, M.H. "Obsessions, compulsions, motivation, and responsibility for harm", Australian Journal of Psychology, 53, 1-6. 2001.

[6] Julien, D., O’Connor, K.P. and Aardema, F., "Intrusive thoughts, obsessions, and appraisals in obsessive-compulsive disorder: A critical review”, Clinical Psychology Review, 27. 366-383. 2007.

[7] Taylor, S., Coles, M. E., Abramowitz, J. S., Wu, K. D., Olatunji, B. O., Timpano, K. R., McKay, D., Se-Kang, K., Carmin, C and Tolin, D.F., "How are dysfunctional beliefs related to obsessivecompulsive symptoms?”, Journal of Cognitive Psychotherapy, 24, 165-176. 2001

[8] Cisler J.M., Brady R.E., Olatunji B.O. and Lohr J.M., "Disgust and obsessive beliefs in contamination-related OCD”, Cognitive Therapy and Research, 34, 439-448.2010.

[9] Mather A. and Cartwright-Hatton S., "Cognitive predictors of obsessive-compulsive symptoms in adolescence: a preliminary investigation”, Journal of Clinical Child and Adolescent Psychology, 33, 743-749. 2004.

[10] Tolin, D.F., Worhunsky, P. and Maltby, N., "Are "obsessive" beliefs specific to OCD? A comparison across anxiety disorders", Behaviour Research and Therapy, 44. 469-480. 2006.

[11] Olatunji B.O., Davis M.L., Powers M.B. and Smits J.A.J. "Cognitive-behavioural therapy for obsessive-compulsive disorder: A meta-analysis of treatment outcome and moderators", Journal of Psychiatric Research, 47, 33-41. 2013.
[12] Pozza, A., Coradeschi, D. and Dèttore, D., "Do dysfunctional beliefs moderate the negative influence of comorbid severe depression on outcome of residential treatment for refractory OCD? A pilot study", Clinical Neuropsychiatry, 10. 72-83. 2013.

[13] Coradeschi, D., Pozza, A., Mannelli, E., Mengoli, G., Rotundo, L., Neri, T. and Dèttore, D., "Obsessive belief changes in patients with resistant OCD treated daily with prolonged exposure and response prevention”, Psicoterapia Cognitiva e Comportamentale, 18, 23-37. 2012.

[14] Longmore, R.J., Worrell, M., "Do we need to challenge thoughts in cognitive behaviour therapy?”, Clinical Psychology Review, 27, 173-187. 2007.

[15] Salkovskis, P.M., Richards, H.C. and Forrester, E., "The relationship between obsessional problems and intrusive thoughts", Behavioural and Cognitive Psychotherapy, 23, 281-299. 1995.

[16] Starcevic, V. and Berle, D., "Cognitive specificity of anxiety disorders: A review of selected key constructs", Depression and Anxiety, 23, 51-61. 2006.

[17] Torres, A.R., Prince, M.J., Bebbington, P.E., Bhugra, D., Brugha, T.S., Farrell, M., Jenkins, R., Lewis, G., Meltzer, M. and Singleton, N., "Obsessive-compulsive disorder: prevalence, comorbidity, impact, and help-seeking in the British National Psychiatric Morbidity Survey of 2000”, American Journal of Psychiatry, 163, 1978-1985. 2006.

[18] Crino, R. and Andrews, G., "Obsessive-compulsive disorder and axis I comorbidity”, Journal of Anxiety Disorders, 19, 37-46. 1996

[19] Persons, J.B. and Silberschatz, G., "Are results of randomized controlled trials useful to psychotherapists?”, Journal of Clinical and Consulting Psychology, 66, 126-135. 1998.

[20] American Psychiatric Association, "The Diagnostic and Statistical Manual of Mental Disorders: DSM 5”, bookpointUS. 2013.

[21] Behling, O. and Law, K.S. Translating questionnaires and other research instruments: Problems and solutions. Sage, Thousand Oaks. 2002.

[22] Obsessive Compulsive Cognitions Working Group, "Psychometric validation of the Obsessive Beliefs Questionnaire and the Interpretation of Intrusions Inventory: Part I”, Behaviour Research and Therapy, 41, 863. 2003.

[23] Obsessive Cognitions Working Group, "Psychometric validation of the obsessive belief questionnaire and interpretation of intrusions inventory-Part 2: Factor analyses and testing of a brief version”, Behaviour Research and Therapy, 43. 1527-1542. 2005.

[24] Salkovskis, P.M., Wroe, A., Gledhill, A., Morrison, N., Forrester, E., Richards, C., Reynolds, M. and Thorpe, S., "Responsibility attitudes and interpretations are characteristics of obsessive compulsive disorder”, Behaviour Research and Therapy, 38, 347372. 2000.

[25] Ray, J.E. and Shadish, W.R., "How interchangeable are different measures of effect size?", Journal of Consulting and Clinical Psychology, 64, 1316-1325. 1996.

[26] Hedges, L., "Distribution theory for Glass' estimator of effect size and related estimators", Journal of Educational Statistics, 6, 107128. 1981.

[27] Cohen, J. Statistical power analysis for the behavioural sciences (2nd ed.). Erlbaum, Hillsdale, NK. 1988.

[28] Borenstein, M., Hedges. L.V., Higgins, J.P.T. and Rothstein, H.R. Introduction to meta-analysis. John Wiley \& Sons, Chichester. 2009.

[29] Higgins, J.P.T., Thompson, S.G., Deeks, J.J. and Altman, D.G., "Measuring inconsistency in meta-analyses", British Medical Journal, 327, 557-560. 2003.

[30] Hedges, L.V. and Olkin, I. Statistical methods for meta-analysis. Academic Press, San Diego, CA. 1985.

[31] Rosenthal, R. Meta-analytic procedures for social research. Sage, London. 1991.

[32] Sterne, J.A.C. and Egger, M. Regression methods to detect publication and other bias in meta-analysis. In HR Rothstein, AJ Sutton, M Borenstein (Eds.), Publication bias in meta-analysis: Prevention, assessment and adjustments (pp. 99-100). Wiley, Chichester. 2005.

[33] Anholt, G.E., Emmelkamp, P.M., Cath, D.C., van Oppen, P., Nelissen, H. and Smit, J.H., "Do patients with OCD and pathological gambling have similar dysfunctional cognitions?”, Behaviour Research and Therapy, 42. 529-537. 2004.

[34] Anholt, G.E., Cath, D.C., Emmelkamp, P.M., Van Oppen, P., Smit, J.H., and van Balkom, A.J. "Do obsessional beliefs discriminate OCD without tic patients from OCD with tic and Tourette's 
syndrome patients?”, Behaviour Research and Therapy, 44. 15371543. 2006.

[35] Wolters, L.H., Hogendoorn, S.M., Koolstra, T., Vervoort, L., Boer, F., Prins, P.J.M. and de Haan, "Psychometric properties of a Dutch version of the Obsessive Beliefs Questionnaire- Child Version (OBQ-CV)”, Journal of Anxiety Disorders, 25, 714-721. 2011.

[36] Biglieri, R.R., "Cognitive profile of obsessive-compulsive disorder patients: preliminary data”, Anuario de Investigaciones, 15. 43-50. 2008.

[37] Biglieri, R.R., Vetere, G, “Adaptación argentina del Cuestionario de Creencias Obsesivas; Argentinian adaptation of the Obsessive Beliefs Questionnaire”, Interdisciplinaria, 25. 53-76. 2008.

[38] Chik, H.M., Calamari, J.E., Rector, N.A., and Riemann, B.C., "What do low-dysfunctional beliefs obsessive-compulsive disorder subgroups believe?”, Journal of Anxiety Disorders, 24 837-846. 2010.

[39] Tolin, D.F., Brady, R.E. and Hannan, S., "Obsessional beliefs and symptoms of obsessive-compulsive disorder in a clinical sample”, Journal of Psychopathology and Behavioural Assessment, 3. 3142. 2008.

[40] Tolin DF, Worhunsky P, Maltby N., “Are "obsessive” beliefs specific to OCD? A comparison across anxiety disorders”, Behaviour Research and Therapy 44, 469-480. 2006.

[41] Viar, M.A., Bilsky, S.A., Armstrong, T. and Olatunji, B.O., "Obsessive beliefs and dimensions of obsessive-compulsive disorder: An examination of specific associations", Cognitive Therapy and Research 35. 108-117. 2011.

[42] Cougle, J.R., Lee, H. and Salkovskis, P.M., "Are responsibility beliefs inflated in non-checking OCD patients?” Journal of Anxiety Disorders 21. 153-159. 2007.

[43] Gordon, O.M., Salkovskis, P.M., Oldfield, V.B. and Carter, N. "The association between obsessive compulsive disorder and obsessive compulsive personality disorder: Prevalence and clinical presentation”, British Journal of Clinical Psychology 52. 300-315. 2013.

[44] Libby, S., Reynolds, S., Derisley, J. and Clark, S., "Cognitive appraisals in young people with obsessive-compulsive disorder", Journal of Child Psychology and Psychiatry 45. 1076-1084. 2004.

[45] Ghassemzadeh, H., Bolhari, J., Birashk, B. and Salavati, M., "Responsibility attitude in a sample of Iranian obsessivecompulsive patients", International Journal of Social Psychiatry, 51. 13-22. 2005.

[46] Izadi, R., Asgari, K., Hamidtaher, N. and Abedi, M., "Assessment of obsessive beliefs in individuals with obsessive-compulsive disorder in comparison to healthy sample”, International Journal of Psychology and Counselling 4. 81-85. 2012.

[47] Julien, D., Careau, Y., O’Connor, K.P., Bouvard, M., Rhéaume, J., Langlois, F., Freeston, M.H., Radomsky, A.S. and Cottraux, J., "Specificity of belief domains in CD: Validation of the French version of the Obsessive Beliefs Questionnaire and a comparison across samples”, Journal of Anxiety Disorders 22. 1029-1041. 2008.

[48] Radomsky, A.S., Ausbaugh, A.R. and Gelfand, L.A., "Relationship between anger, symptoms, and cognitive factors in OCD checkers”, Behaviour Research and Therapy 45. 2712-2725. 2007.

[49] Novara, C., Pastore, M., Sica, C. and Sanavio, E., "Presentazione della versione italiana dell'Obsessive Beliefs Questionnaire (OBQ): struttura fattoriale e analisi di attendibilità (parte I)”, Psicoterapia Cognitiva e Comportamentale 15, 139-70. 2009.

[50] Sica, C., Coradeschi, D., Sanavio, E., Dorz, S., Manchisi, D. and Novara, C., "A study of the psychometric properties of the Obsessive Beliefs Inventory and Interpretations of Intrusions Inventory on clinical Italian individuals”, Journal of Anxiety Disorders 18, 291-307. 2004.

[51] Yorulmaz, O., Karanci, A.N., Bastug, B., Kisa, C. and Goka, E., "Responsibility, thought-action fusion, and thought suppression in Turkish patients with obsessive-compulsive disorder", Journal of Clinical Psychology 64, 308-317. 2008.

[52] Salkovskis, P.M., "Understanding and treating obsessivecompulsive disorder”, Behaviour Research and Therapy 37, S29S52. 1999.

[53] Campbell-Sills, L., Barlow, D.H., Brown, T. A., and Hofmann, S.G., "Acceptability and suppression of negative emotion in anxiety and mood disorders”, Emotion 6, 587. 2006.

[54] Ellard, K.K., Fairholme, C.P., Boisseau, C.L., Farchione, T.J., Barlow, D.H., "Unified protocol for the transdiagnostic treatment of emotional disorders: Protocol development and initial outcome data”, Cognitive and Behavioral Practice 17, 88-101. 2010.

[55] Vos, S.P., Huibers, M.J., Arntz, A. "Experimental investigation of targeting responsibility versus danger in cognitive therapy of obsessive-compulsive disorder", Depression and anxiety 29, 629637. 2012.

[56] Menzies, R.G., Harris, L.M., Cumming, S.R., Einstein, D.A., “The relationship between inflated personal responsibility and exaggerated danger expectancies in obsessive-compulsive concerns”, Behaviour Research and Therapy 38, 1029-1037. 2000.

[57] Rachman, S., Shafran, R., "Cognitive and behavioral features of obsessive-compulsive disorder”, Obsessive-compulsive disorder: Theory, research, and treatment, 51-78.

Appendix A. Characteristics of the cross-sectional case-control studies included in the meta-analysis $(n=22)$.

\begin{tabular}{|c|c|c|c|c|c|c|c|c|}
\hline Study name & $\begin{array}{c}\text { Publication } \\
\text { date }\end{array}$ & Country & Cohort & $n$ & $\begin{array}{c}\text { Control } \\
\text { group }\end{array}$ & $\begin{array}{c}\text { Healthy control } \\
\text { participants }\end{array}$ & $\begin{array}{c}\text { Instruments used } \\
\text { to make OCD } \\
\text { diagnoses }\end{array}$ & $\begin{array}{c}\text { Inflated } \\
\text { responsibility } \\
\text { beliefs measures }\end{array}$ \\
\hline Anholt & 2004 & $\begin{array}{l}\text { The } \\
\text { Netherlands }\end{array}$ & Adults & 91 & $\mathrm{HC}, \mathrm{ADC}$ & $\begin{array}{l}\text { Screened individuals } \\
\text { from the general } \\
\text { population }\end{array}$ & SCID-I & OBQ-87 \\
\hline Anholt & 2006 & $\begin{array}{l}\text { The } \\
\text { Netherlands }\end{array}$ & Adults & 80 & $\mathrm{HC}$ & $\begin{array}{c}\text { Screened individuals } \\
\text { from the general } \\
\text { population }\end{array}$ & SCID-I & OBQ-87 \\
\hline $\begin{array}{l}\text { Biglieri } \\
\text { \&Vetere }\end{array}$ & 2008 & Brazil & Adults & 110 & $\mathrm{HC}, \mathrm{ADC}$ & $\begin{array}{l}\text { Screened individuals } \\
\text { from the general } \\
\text { population }\end{array}$ & SCID-I & OBQ-31 \\
\hline Biglieri & 2008 & Brazil & Adults & 59 & $\mathrm{HC}$ & $\begin{array}{c}\text { Screened individuals } \\
\text { from the general } \\
\text { population }\end{array}$ & SCID-I & OBQ-31 \\
\hline Chik & 2010 & USA & Adults & 136 & $\mathrm{HC}$ & Unscreened students & ADIS-IV, SCID-I & OBQ-44 \\
\hline Cougle & 2007 & UK & Adults & 151 & $\mathrm{HC}, \mathrm{ADC}$ & $\begin{array}{c}\text { Unscreened } \\
\text { individuals from the } \\
\text { general population }\end{array}$ & SCID-I & RAS \\
\hline Ghassemzadeh & 2005 & Iran & Adults & 40 & $\mathrm{HC}, \mathrm{ADC}$ & $\begin{array}{c}\text { Unscreened } \\
\text { individuals from the } \\
\text { general population }\end{array}$ & $\begin{array}{l}\text { Interview based } \\
\text { on the DSM-IV }\end{array}$ & RAS \\
\hline Gordon & 2013 & UK & Adults & 43 & $\mathrm{HC}$ & $\begin{array}{l}\text { Screened individuals } \\
\text { from the general } \\
\text { population }\end{array}$ & SCID-I & RAS \\
\hline Izadi & 2012 & Iran & Adults & 113 & $\mathrm{HC}$ & $\begin{array}{l}\text { Screened family } \\
\text { members of the } \\
\text { patients with OCD }\end{array}$ & $\begin{array}{l}\text { Interview based } \\
\text { on the DSM-IV- } \\
\text { TR }\end{array}$ & OBQ-44 \\
\hline Julien & 2008 & Canada & Adults & 523 & $\mathrm{HC}, \mathrm{AD}$ & $\begin{array}{c}\text { Unscreened } \\
\text { undergraduates }\end{array}$ & $\begin{array}{l}\text { ADIS-IV, SCID-I, } \\
\text { Interview based }\end{array}$ & OBQ-44 \\
\hline
\end{tabular}




\begin{tabular}{|c|c|c|c|c|c|c|c|c|}
\hline & & & & & & & on the DSM-IV & \\
\hline Libby & 2004 & UK & $\begin{array}{c}\text { Children/ } \\
\text { adolescents }\end{array}$ & 73 & $\mathrm{HC}, \mathrm{AD}$ & $\begin{array}{c}\text { Unscreened } \\
\text { individuals from the } \\
\text { general population }\end{array}$ & ADIS-C/P & RAS \\
\hline Novara & 2009 & Italy & Adults & 85 & $\mathrm{HC}, \mathrm{AD}$ & $\begin{array}{c}\text { Unscreened } \\
\text { undergraduates }\end{array}$ & SCID-I & OBQ-46 \\
\hline OCCWG & 2003 & $\begin{array}{c}\text { Multicentre } \\
\text { study }\end{array}$ & Adults & 1217 & $\mathrm{HC}, \mathrm{AD}$ & $\begin{array}{c}\text { Screened } \\
\text { undergraduates and } \\
\text { individuals from the } \\
\text { general population }\end{array}$ & $\begin{array}{l}\text { SCID-I, ADIS-IV, } \\
\text { Interview based } \\
\text { on the DSM-IV }\end{array}$ & OBQ-87, III \\
\hline OCCWG & 2005 & $\begin{array}{c}\text { Multicentre } \\
\text { study }\end{array}$ & Adults & 402 & $\mathrm{HC}, \mathrm{AD}$ & $\begin{array}{c}\text { Unscreened } \\
\text { undergraduates and } \\
\text { individuals from the } \\
\text { general population }\end{array}$ & SCID-I, ADIS-IV & OBQ-44 \\
\hline Radomsky & 2007 & Canada & Adults & 170 & $\mathrm{HC}$ & $\begin{array}{c}\text { Unscreened } \\
\text { undergraduates }\end{array}$ & ADIS-IV & OBQ-44 \\
\hline Salkovskis & 2000 & UK & Adults & 150 & $\mathrm{HC}, \mathrm{AD}$ & $\begin{array}{c}\text { Unscreened } \\
\text { undergraduates and } \\
\text { individuals from the } \\
\text { general population }\end{array}$ & SCID-I & RAS \\
\hline Sica & 2004 & Italy & Adults & 77 & $\mathrm{HC}, \mathrm{AD}$ & $\begin{array}{c}\text { Unscreened } \\
\text { undergraduates }\end{array}$ & SCID-I & OBQ-87, III \\
\hline Tolin & 2006 & USA & Adults & 142 & $\mathrm{HC}, \mathrm{AD}$ & $\begin{array}{c}\text { Screened individuals } \\
\text { from the general } \\
\text { population } \\
\end{array}$ & ADIS-IV & OBQ-44 \\
\hline Tolin & 2007 & USA & Adults & 112 & $\mathrm{AD}$ & $\begin{array}{l}\text { Information not } \\
\text { reported }\end{array}$ & ADIS-IV & OBQ-44 \\
\hline Viar & 2011 & USA & Adults & 60 & $\mathrm{HC}$ & $\begin{array}{c}\text { Screened individuals } \\
\text { from the general } \\
\text { population } \\
\end{array}$ & SCID-I & OBQ-44 \\
\hline Wolters & 2011 & Netherlands & $\begin{array}{c}\text { Children/ } \\
\text { adolescents }\end{array}$ & 594 & $\mathrm{HC}$ & $\begin{array}{c}\text { Unscreened } \\
\text { individuals from the } \\
\text { general population }\end{array}$ & ADIS-C/P & OBQ-CV \\
\hline Yorulmaz & 2008 & Turkey & Adults & 98 & $\mathrm{HC}, \mathrm{AD}$ & $\begin{array}{c}\text { Unscreened } \\
\text { individuals from the } \\
\text { general population }\end{array}$ & $\begin{array}{c}\text { Interview based } \\
\text { on the DSM-IV- } \\
\text { TR }\end{array}$ & RAS \\
\hline
\end{tabular}

Note. $\mathrm{AD}=$ Anxiety disorder patients as controls; ADIS-C/P= Anxiety Disorders Interview Schedule for Children and Parents; ADIS-IV= Anxiety Disorders Interview Schedule; HC= Healthy controls; III= Interpretations of Intrusions Inventory; OBQ-31= Obsessive Beliefs Questionnaire-31; OBQ44= Obsessive Beliefs Questionnaire-44; OBQ-46= Obsessive Beliefs Questionnaire-46; OBQ-87= Obsessive Beliefs Questionnaire-87; OBQ-CV= Obsessive Beliefs Questionnaire-Children Version; OCCWG= Obsessive Compulsive Cognitions Working Group; OCD= Obsessive compulsive disorder; RAS= Responsibility Attitudes Scale 